\title{
Conjoint muscle free flap for obliteration of an upper thoracic empyema cavity
}

\author{
Geoffrey G Hallock MD
}

GG Hallock. Conjoint muscle free flap for obliteration of an upper thoracic empyema cavity. Can J Plast Surg 2003;11(4):216-218.

Successful obliteration of an empyema cavity with vascularized flaps can, on occasion, best be accomplished using a free tissue transfer. A conjoint free muscle flap captures the immunological attributes of muscle necessary in the infectious milieu of these defects, augments the potential flap volume required to fill these often large defects, yet relies on only a single recipient site for the requisite microanastomoses. These advantages are demonstrated by a case using a combined latissimus dorsi/serratus anterior conjoint muscle free flap to obliterate a chronic upper thoracic empyema cavity. The internal mammary vessels were the most readily accessible recipient site, and should be considered an important alternative when managing these challenging wounds of the upper chest.

Key Words: Combined conjoint muscle free flap; Empyema cavity

\section{La constatation d'une morbidité potentielle après l'utilisation de l'artère radiale comme conduit de revascularisation de l'artère coronaire}

\begin{abstract}
L'utilisation de l'artère radiale comme conduit vasculaire de rechange dans le cadre d'un pontage coronarien gagne en popularité. L'expérience de la chirurgie plastique au moyen de lambeaux radiaux de l'avant-bras démontre toutefois que le sacrifice de l'artère radiale n'est pas toujours une manœuvre bénigne. La morbidité potentielle après l'utilisation de cette zone de prélèvement en ce qui a trait à la dysfonction de la main ou de problèmes de cicatrisation de la plaie peut être importante, et il faut souvent recourir à la chirurgie reconstructive. Des exemples de cas de nécrose cutanée, d'infection subséquente de la plaie à l'avant-bras et de cicatrisation hypertrophique après le prélèvement de l'artère radiale sont présentés pour démontrer qu'il s'agit là d'une véritable préoccupation et pour permettre de réviser tout le spectre de problèmes potentiels s'y rapportant. Dans tout processus de sélection qui oblige à choisir l'artère radiale comme conduit de revascularisation coronaire, il faut prévoir ce type de complications dans la zone de prélèvement.
\end{abstract}

$\mathrm{T}$ he goal in the treatment of a recalcitrant empyema cavity is to eradicate the infection and obtain rapid wound healing with a minimum of surgical procedures (1-3). Complete obliteration of the infected space may require filling using well-vascularized tissue transfers. Many local flaps are capable of accomplishing this objective, including the latissimus dorsi $(2,4-7)$, serratus anterior $(1,4)$, pectoralis major (7), trapezius (7) and intercostal muscles (5), the pedicled TRAM flap (8), and the omentum (7). However, the availability of these relatively simple options may be limited due to prior surgical incisions (eg, a posterolateral thoractomy), previous use of that specific flap, location of the defect outside the arc of rotation of that flap or inadequate size (5).

The lack of local flap options would be the prime justification for the use of a free flap, and almost all of the aforementioned donor sites have been used in this regard as well $(9,10)$. This includes the use of combined flaps to augment the total volume often needed to fill these large wounds $(3,11)$. Most frequently, the ipsilateral thoracodorsal vessels has served as the recipient site for microanastomoses $(3,9-11)$. The internal mammary vessels have been overlooked in this role, but this may be the most practical alternative for upper chest empyema cavities, as shown in this recent experience (12).

\section{CASE PRESENTATION}

Following a right upper lobectomy via a posterolateral thoractomy for non-small cell carcinoma, a 52-year-old man sustained a massive postoperative hemorrhage with subsequent empyema, which was controlled by the removal of the anterior third rib and intrathoracic transposition of the right pectoralis major muscle. The empyema recurred, and was again drained anteriorly, this time leaving a skin window open to the large upper thoracic cavity (Figure 1). Following multiple debridements and irrigations, a persistent, clean granulating wound was obtained (Figure 2).

Because all potential adjacent muscle flaps had been either divided or used previously, and a TRAM or pedicled omental flap probably could not reach the upper chest, it was elected to use a free muscle flap instead. With the patient in a slightly oblique left lateral decubitus position, access to the sternum was readily possible through the prior incision used to harvest his pectoralis major muscle. To minimize any risk from prior scarring or radiation fibrosis, the left internal mammary vessels were then explored by removing the third costal cartilage. Both the artery and the vein were found to be pliable and of large caliber.

The left latissimus dorsi muscle was elevated, but in this cachetic man was extremely thin. Therefore, the lower five 


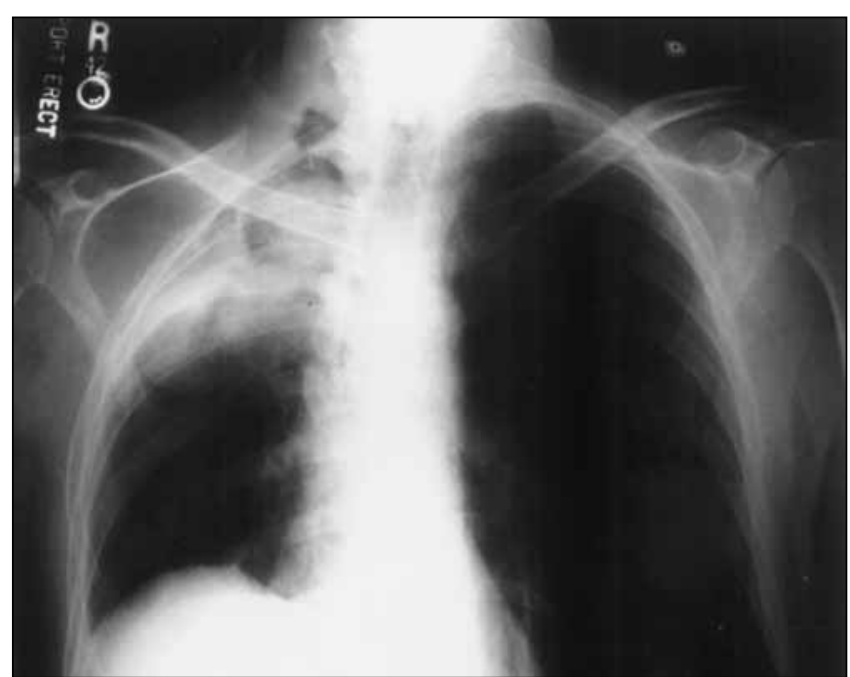

Figure 1) Large right upper thoracic empyema cavity seen on posteroanterior chest $x$-ray with an extensive mottled infiltrate before drainage

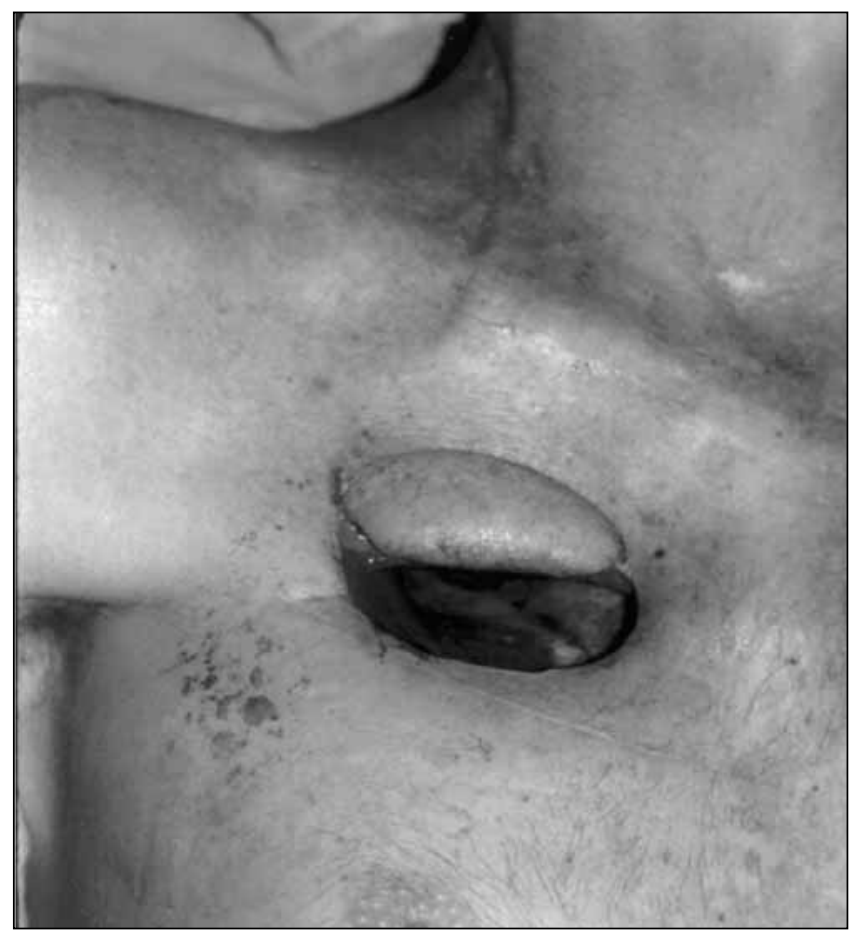

Figure 2) Right upper chest skin window to large right upper thoracic empyema cavity

slips in toto of the serratus anterior muscle were also raised, maintaining the serratus branch of the thoracodorsal artery to create a combined conjoint free muscle flap based on a common thoracodorsal pedicle (Figure 3). Both arterial and venous microanastomosis were performed in end-to-side fashion to the substantially larger internal mammary vessels (Figure 4). Both muscles in sequence were stuffed into the depths of the right chest cavity with volume to spare, so that the skin paddle on the latissimus muscle could be discarded and the skin used as a split thickness skin graft over the exposed muscle. Wound healing was then uneventful (Figure 5), and total empyema

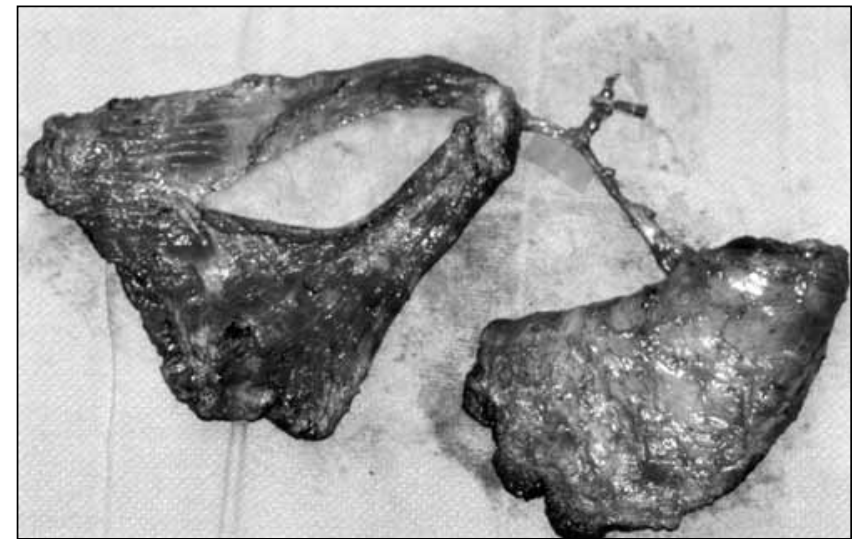

Figure 3) Conjoint left latissimus dorsi myocutaneous and serratus anterior free muscle flap (microclamp on common thoracodorsal pedicle)

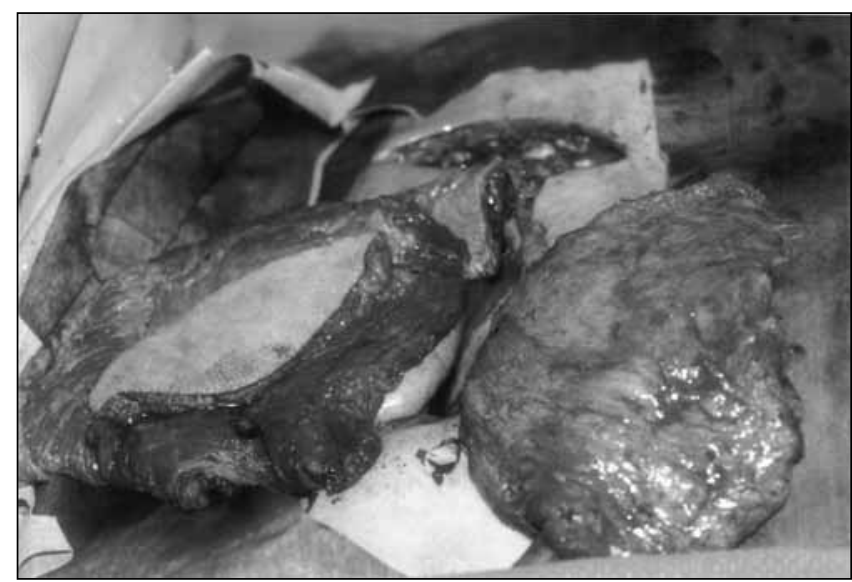

Figure 4) Muscle flaps on chest before placement into the cavity. The left internal mammary vessels near the midline incision (above) served as the recipient site

cavity obliteration was achieved, as documented by chest $\mathrm{x}$-ray (Figure 6).

\section{DISCUSSION}

If local flaps are unavailable or inadequate for total obliteration of an empyema cavity, a possible solution is a thoracoplasty to diminish the volume that must be filled (7). This maneuver is not without its own attendant morbidity, including the potential of a significant cosmetic deformity. A free flap might then be preferable, especially to gain the immunological advantages of muscle (13), but a single muscle also might not be large enough (9).

The use of sequential (14) or chain-link free flaps to piece several flaps together via flow-through microanastomoses would be a very complex method just to augment flap volume (11). Instead, a conjoint muscle free flap (14), as exemplified in this case report by the combined latissimus dorsi and serratus anterior muscle flap, has been previously confirmed to be efficacious by Chen et al (3) and others (10). The conjoint flap type permits the transfer of multiple muscles from a single donor site, that are joined by a common source vessel so that only one arterial and one venous microanastomosis must be performed. A unique precaution though is that viability of one 


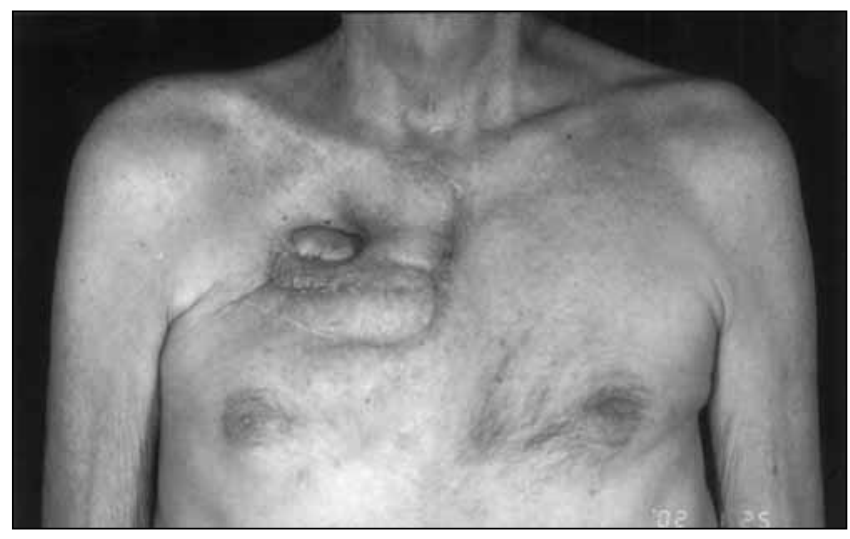

Figure 5) External healed wound two months later

flap does not insure that of any other, so all parts require adequate post-operative monitoring (4).

In most previous experiences when a free flap had been necessary to close a thoracic space, the thoracodorsal vessels were most commonly used as the recipient site $(3,9-11)$, although the transverse cervical $(9,10)$ and even the common carotid artery (10) have also been used. Some surgeons have intentionally avoided the internal mammary vessels, especially if they are located near an irradiated field (10). On the contrary, we have found the internal mammary vessels to actually be more accessible than working within the depths of the axilla, and any associated fibrosis actually facilitates all technical maneuvering as this limits movement of the chest during respirations.

\section{CONCLUSIONS}

If the usual simple solutions (eg, local flaps) are ineffective for eliminating an infected empyema cavity, then free flaps may have an important role. A conjoint free flap permits the simultaneous transfer of multiple flaps to augment total flap volume,

\section{REFERENCES}

1. Arnold PG, Pairolero PC, Waldorf JC. The serratus anterior muscle: Intrathoracic and extrathoracic utilization. Plast Reconstr Surg 1984;73:240-6.

2. Arnold PG, Pairolero PC. Intrathoracic muscle flaps in the surgical management oflife-threatening hemorrhage from the heart and great vessels. Plast Reconstr Surg 1988;81:831-5.

3. Chen HC, Tang YB, Noordhoff MS, Chang CH. Microvascular free muscle flaps for chronic empyema with bronchopleural fistula when the major local muscles have been divided - one-stage operation with primary wound closure. Ann Plast Surg 1990;24:510-6.

4. Takayanagi S, Ohtsuka M, Tsukie T. Use of the latissimus dorsi and the serratus anterior muscles as a combined flap. Ann Plast Surg 1988;20:333-9.

5. Paletta EC, Huang DB. Intrathoracic application of the reverse latissimus dorsi muscle flap. Ann Plast Surg 1999;43:227-31.

6. Shesol BF, Clarke JS. Intrathoracic application of the latissimus dorsi muscuocutaneous flap. Plast Reconstr Surg 1980;66:842-5.

7. Michaels MB, Orgill DP, Decamp MM, Pribaz JJ, Eriksson E, Swanson S. Flap closure of postpneumonectomy empyema. Plast Reconstr Surg 1997;99:437-42.

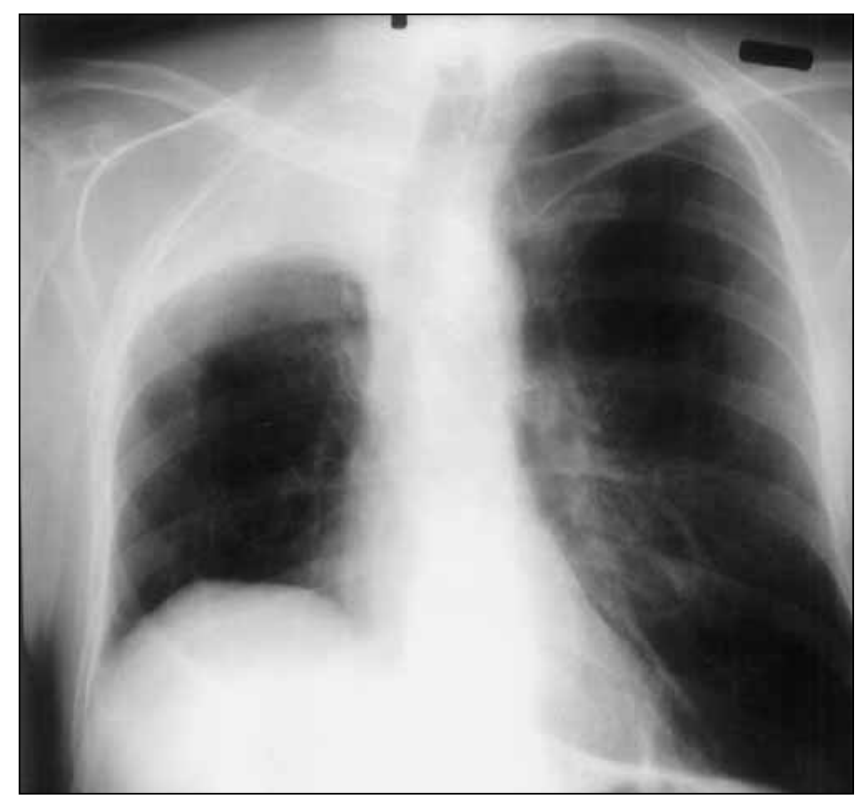

Figure 6) The right upper thoracic homogeneous opacity seen on this chest $x$-ray corresponds to the conjoint muscle flaps

has a single common source vessel, and therefore needs only one recipient site for microanastomoses. The internal mammary vessels should be considered as a reliable alternative as the extrathoracic recipient site for intrathoracic microsurgical composite tissue transfers, particularly if they are needed to obliterate the upper thoracic cavity.

ACKNOWLEDGEMENTS: David C Rice BS, Director, Advanced Clinical Technologies Department, assisted with the microsurgery. The thoracic service provided medical management of this patient. Both are associated with the Lehigh Valley Hospital, Allentown, Pennsylvania, USA.

8. Hallock GG. Intrathoracic application of the transverse rectus abdominis musculocutaneous flap. Ann Plast Surg 1992;29:357-61

9. Perkins DJ, Lee KK, Pennington DB, Stern HS. Free flaps in the management of intrathoracic sepsis. Br J Plast Surg 1995;48:546-50.

10. Hammond DC, Fisher J, Meland NB. Intrathoracic free flaps. Plast Reconstr Surg 1993;91:1259-64.

11. Rand RP, Maser B, Dry G, Vallieres E. Reconstruction of irradiated postpneumonectomy empyema cavity with chain-link coupled microsurgical omental and TRAM flaps. Plast Reconstr Surg 2000;105:183-6

12. Hefel L, Schwabegger A, Ninkovic M, et al. Internal mammary vessels: Anatomical and clinical considerations. Br J Plast Surg 1995; 48:527-32.

13. Gosain A, Chang N, Mathes SJ, Hunt TK, Vasconez L. A study of the relationship between blood flow and bacterial inoculation in musculocutaneous and fasciocutaneous flaps. Plast Reconstr Surg 1990;86:1152-6.

14. Hallock GG. Simplified nomenclature for compound flaps. Plast Reconstr Surg 2000;105:1465-70. 